\title{
A new non-muscle-invasive bladder tumor-homing peptide identified by phage display in vivo
}

\author{
XIAOFENG YANG ${ }^{1 *}$, FAN ZHANG $^{2 *}$, JUNQIAN LUO $^{3}$, JIANZHI PANG $^{3}$, SANHUA YAN $^{3}$, \\ FANG LUO ${ }^{3}$, JIEHAO LIU $^{3}$, WEI WANG ${ }^{3}$, YONGPING CUI ${ }^{4}$ and XIXI $\mathrm{SU}^{3}$
}

\begin{abstract}
${ }^{1}$ Department of Urology, The First Hospital, Shanxi Medical University; ${ }^{2}$ Department of Microbiology and Immunology, Shanxi Medical University; ${ }^{3}$ Shanxi Medical University, Graduate School, Shanxi Medical University; ${ }^{4}$ Key Laboratory of Cellular Physiology, Ministry of Education, Shanxi Medical University, Taiyuan, Shanxi 030001, P.R. China
\end{abstract}

Received January 13, 2016; Accepted February 24, 2016

DOI: $10.3892 /$ or.2016.4829

\begin{abstract}
Bladder cancer is common and widespread, and its incidence is increasing. Many new diagnostic methods combined with state-of-the-art technology have been introduced in cystoscopy to collect real-time images of the bladder mucosa for diagnosis, but often miss inconspicuous early-stage tumors. Fluorophore-labeled peptides with high sensitivity and specificity for cancer would be a desirable tool for the detection and treatment of tiny or residual bladder tumors. Phage display and the human non-muscle-invasive bladder cancer cell line BIU-87 were used to identify a peptide. The isolated phage display peptide (CSSPIGRHC, named NYZL1) was tested in vitro for its binding specificity and affinity. Accumulation into xenograft tumors in a nude mouse model was analyzed with FITC-labeled NYZL1. NYZL1, with strong tumor-homing ability, was identified by in vivo phage library selection in the bladder cancer model. The NYZL1 phage and synthetic FITC-labeled NYZL1 peptides bound to tumor tissues and cells, but were hardly detected in normal control organs. Notably, accumulation of FITC-NYZL1 in bladder tumor cells was time-dependent. Biodistribution studies of xenografts of BIU-87 cells showed accumulation of injected FITC-NYZL1 in the tumors, and the bound peptide could not be removed by perfusion after $24 \mathrm{~h}$. The mouse model of
\end{abstract}

Correspondence to: Dr Xiaofeng Yang, Department of Urology, The First Hospital, Shanxi Medical University, 85 South Jiefang Road, Taiyuan, Shanxi 030001, P.R. China

E-mail: xfyang170@sina.com

Dr Fan Zhang, Department of Microbiology and Immunology, Shanxi Medical University, 56 South Xinjian Road, Taiyuan, Shanxi 030001, P.R. China

E-mail: zhangfan11688@126.com

*Contributed equally

Key words: non-muscle-invasive bladder tumor, in vivo phage display, tumor-homing peptide, optical molecular imaging, targeted diagnosis bladder tumor showed increased fluorescence intensity in the tumor-bearing bladder in comparison with normal bladder tissues after 4-6 h. In conclusion, NYZL1 may represent a lead peptide structure applicable in the development of optical molecular imaging.

\section{Introduction}

Bladder cancer is a common disease worldwide. At any point in time 2.7 million people have a history of bladder cancer (1). Most cases of bladder cancer are non-muscle invasive at initial diagnosis (2). In non-muscle-invasive bladder cancer (NMIBC), $\sim 75 \%$ of patients present with stage pTa, pT1 or carcinoma in situ (CIS) lesions (3). Generally, NMIBC prognosis is good, although $30-80 \%$ cases may show recurrence, with $1-45 \%$ progressing to muscle invasion within 5 years (3-5). Consequently, NMIBC is a chronic disease with varying oncologic outcomes requiring frequent follow-up and repeated treatments with cystoscopy, making the cost per patient from diagnosis to death the highest of all cancers $(6,7)$.

Recent diagnostic methods combined with state-of-theart technology have been introduced in cystoscopy to collect real-time in vivo histological images of the bladder mucosa for diagnosis (8), and endoscopic molecular imaging can detect molecular changes in diseased cells within the mucosa. This discipline has great potential to improve medicine via detection of diseases in early stages $(9,10)$. Application of molecular imaging to endoscopy for the diagnosis and treatment of cancer may increase the efficiency of endoscopic screening and surveillance. An important advantage of performing molecular imaging of the mucosa is the opportunity to apply exogenous probes (11). Several different classes of probe technology have been developed to perform molecular imaging, including antibodies, antibody fragments, peptides, nanoparticles and activatable probes $(12,13)$.

Peptide-based delivery of compounds has numerous advantages over other delivery systems. Peptides are smaller in size and penetrate more efficiently into tissue compared to antibodies. In addition, peptides are synthesized by automated techniques with low production costs, which makes them even more popular (14). Two cyclic bladder cancer-homing peptides have been identified to date. The first peptide, 
CSNRDARRC, was discovered after screening a phage display peptide library on bladder cancer cells (15). The second one is PLZ4 (CQDGRMGFC), which was identified by screening a one-bead-one-compound combinatorial library on bladder cancer (16). PLZ4 not only selectively binds to bladder cancer cell lines but also to primary bladder cancer cells from patients, and not to normal urothelial cells (17). However, the CSNRDARRC and PLZ4 peptides were screened from muscle-invasive bladder cancer cell lines [HT-1376, 5637 (HTB-9), SCaBER, TCCSUP (HTB-5)], whereas 75\% of all patients with bladder cancer present with NMIBC at follow-up with cystoscopy.

The most commonly used cystoscopy, white light cystoscopy (WLC), has several shortcomings. Carcinomas in situ are difficult to visualize and distinguish from benign inflammatory lesions (18), and WLC-guided transurethral resection of NMIBC underscores the shortcomings of WLC in the diagnosis of papillary lesions: inadequate visualization of all tumors that may be present; diffuse tumor borders may result in missed or incompletely resected lesions (19). Therefore, with NMIBC in particular, tumor-homing peptides are very important for cystoscopic optical molecular imaging to visualize residual tumors and carcinomas in situ.

The phage display technology is based on the ability to express foreign polypeptides as fusions to capsid proteins on the surface of bacteriophages; it was first described in 1985 by Smith (20). Phage display has successfully selected peptides specific for molecular signatures or biomarkers in tumor tissue and vasculature. In vitro screening involving the binding of phages to cultured cells has identified peptides specific to tumor cells, such as bladder and lung tumor cells. In vivo screening after intravenous administration of phage libraries has identified peptides that home to diverse pathologic tissues such as cancer and tumor blood vessels. In the present study, we identified a bladder tumor cell-binding peptide using in vivo screening of a phage-display peptide library.

\section{Materials and methods}

Cell lines. The non-muscle-invasive bladder tumor cell line BIU-87 (Chinese human superficial bladder cancer cell line) was kindly provided by Dr Zhou Liqun (Institute of Urology, Peking University, Beijing, China) (21-23). The other bladder tumor T24, E-J and 5637 cell lines were purchased from the Shanghai Ouro Biological Science and Technology Co., Ltd. (Shanghai, China). The cell lines SMMC-7721 (human hepatoma), $\mathrm{SiHa}$ (human cervical cancer), KC (human kidney cancer) and MCF-7 (human breast cancer) were provided by Shanxi Medical Center of Scientific Research (Taiyuan, China). BIU-87, T24, E-J, 5637, KC and SMMC-7721 cells were cultured in RPMI-1640 medium; MCF-7 and SiHa cells were cultured in high-glucose Dulbecco's modified Eagle's medium (DMEM). Each medium was supplemented with $10 \%$ fetal bovine serum (FBS) containing $1 \%$ penicillin and streptomycin. Cells were grown at $37^{\circ} \mathrm{C}$ in $5 \% \mathrm{CO}_{2}$.

Animals. All animal experiments were conducted according to the guidelines of the Laboratory Animals Ethics Committee of Shanxi Medical University. BALB/c nu/nu nude male mice (4-6 weeks) were purchased from Hunan SJA Laboratory
Animal Co. Ltd. (Hunan, China). The model was established as previously reported $(24,25)$ with some modifications. Briefly, a mixture of BIU-87 tumor cells $\left(1 \times 10^{7}\right)$ and basement membrane extract (Matrigel; $200 \mu \mathrm{l}$; BD Biosciences, San Jose, CA, USA) was subcutaneously injected into the forelimb armpits. Visible tumors were formed after $\sim 15$ days.

In vivo phage display biopanning. The Ph.D.-C7C Phage Display Peptide Library kit containing E. coli host strain ER2738 was purchased from New England Biolabs (Beverly, MA, USA). Tumor-bearing mice were intravenously injected with $2 \times 10^{11}$ plaque forming units (PFUs) of phage peptide library via the tail vein. After $15 \mathrm{~min}$, mice were sacrificed and perfused by injection of $50 \mathrm{ml} 0.9 \%$ normal saline through the heart to wash unbound phages. Then, a portion of the tumor and control tissues (liver, kidney, lung and muscle) were harvested and preserved with $4 \%$ formaldehyde. The tumors were manually homogenized and washed with $10 \mathrm{X}$ Trisbuffered saline containing $0.1 \%$ Tween-20 (0.1\% TBST) to remove non-specifically bound phages. Cell membrane-bound phages were eluted with $1 \mathrm{ml}$ of elution buffer $(0.2 \mathrm{M}$ glycine$\mathrm{HCl}, \mathrm{pH} 2.2,1 \mathrm{mg} / \mathrm{ml} \mathrm{BSA}$ ) for $10 \mathrm{~min}$ on ice, and neutralized with $150 \mu 1$ of $1 \mathrm{M}$ Tris- $\mathrm{HCl}$ ( $\mathrm{pH} 9.0$ ). After centrifugation, the supernatant was collected, and the cells in the precipitate were washed once with phosphate-buffered saline (PBS)-BSA and lysed with $0.1 \%$ Triton $\mathrm{X}-100$ for $2 \mathrm{~h}$ at room temperature. Thus, the internalized phages contained in the cell lysate were recovered. A total of $10 \mu 1$ eluted phage was titrated on agar plates in the presence of IPTG/X-gel $(1 \mathrm{mg} / \mathrm{l})$ and tetracycline $(40 \mathrm{mg} / \mathrm{ml})$. The remaining phages were amplified by ER2738 bacteria at $37^{\circ} \mathrm{C}$ for $4.5 \mathrm{~h}$, and injected into tumor-bearing mice to repeat the above procedures. The entire biopanning process was repeated three rounds. At the end of the third round, the phage solution was eluted and titrated on LB/IPTG/X-gel plates. Then, phage clones were randomly selected, and the inserted DNA sequence was determined using the primer: 5'-CCCTCATAGTTAGCGTAACG-3' (New England Biolabs). All peptide library DNA was sequenced using a DNA sequencer following previous protocols (26).

Immunohistochemical staining with phage. In vivo phage localization assays were performed as previously described $(27,28)$. Tumor and control tissues (liver, kidney, lung and muscle), extracted from tumor-bearing mice and preserved in $4 \%$ paraformaldehyde were paraffin-embedded and $4-\mu \mathrm{m}$ sections were obtained. After deparaffinization, the sections were rinsed ( $3 \times 5 \mathrm{~min})$ in PBST (0.01 M PBS, 0.05\% Tween-20; $\mathrm{pH}$ 7.4), and blocked with $3 \%$ hydrogen peroxide-methanol at room temperature for endogenous peroxidase quenching. The sections were then incubated with blocking buffer $(10 \%$ normal goat serum) at room temperature for $30 \mathrm{~min}$, followed by overnight incubation at $4^{\circ} \mathrm{C}$ with rabbit anti-M13 bacteriophage antibody diluted in PBS (1:200). Next, the sections were rinsed in PBST ( $3 \times 5 \mathrm{~min})$ and incubated for $30 \mathrm{~min}$ at $37^{\circ} \mathrm{C}$ with goat anti-rabbit $\operatorname{IgG}(1: 50)$. Detection was carried out with 3,3'-diaminobenzidine (DAB) at room temperature in the dark for $5 \mathrm{~min}$. Counterstaining was performed with hematoxylin. Sections were finally dehydrated, cleared and mounted with neutral resin. For the blank control group, the same steps described above were followed, but the anti-M13 
bacteriophage antibody was replaced by PBS. A ScanScope digital pathology scanning system (Aperio Technologies, Vista, CA, USA) was used to analyze the binding of the phage peptide to tissues.

Cell enzyme-linked immunosorbent assay. After the third round of in vivo screening, 30 blue single colonies were randomly picked from the phage titer plates. Each single colony was amplified, and $1 \times 10^{10} \mathrm{PFU}$ of each colony were stored at $4^{\circ} \mathrm{C}$ until enzyme-linked immunosorbent assay (ELISA) detection.

BIU-87 and iMBT cells (normal human bladder epithelial cells) were plated at a density of $1 \times 10^{4}$ cells/well in a 96 -well plate and incubated at $37^{\circ} \mathrm{C}$ in $5 \% \mathrm{CO}_{2}$ for $24 \mathrm{~h}$. Subsequently, the cells were washed and fixed with $4 \%$ paraformaldehyde for $15 \mathrm{~min}$ at room temperature. After incubation with $3 \%$ $\mathrm{H}_{2} \mathrm{O}_{2}(100 \mu \mathrm{l} /$ well $)$ at $37^{\circ} \mathrm{C}$ for $30 \mathrm{~min}$, the plates were washed 3 times with PBS, and the wells were blocked with $200 \mathrm{ml}$ of $5 \% \mathrm{BSA}$ for $30 \mathrm{~min}$ at $37^{\circ} \mathrm{C}$. The phages $\left(1 \times 10^{10} \mathrm{PFU} /\right.$ well $)$ were added to BIU-87 or iMBT cells and incubated at $37^{\circ} \mathrm{C}$ for 1-2 $\mathrm{h}$. The plates were then washed 3 times with TBST before addition of $100 \mu \mathrm{l}$ HRP-anti-M13 mAb $(1: 5,000)$ for $1 \mathrm{~h}$ at $37^{\circ} \mathrm{C}$. After washing 3 times with $0.05 \%$ TBST, 3,3',5,5'-tetramethylbenzidine (TMB) was added at room temperature for $30 \mathrm{~min}$. The reaction was terminated by the addition of $50 \mu \mathrm{l}$ of $2 \mathrm{M} \mathrm{H}_{2} \mathrm{SO}_{4}$. Subsequently, the plates were read on an automated ELISA plate reader at $450 \mathrm{~nm}$. Unrelated phages with equal titers were added to the wells in place of selected phage clones to serve as negative controls. Selectivity was determined using the following formula: Selectivity $=[\mathrm{BIU}-87$

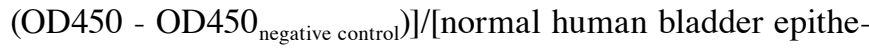
lial cells (OD450 - OD450 $\left.0_{\text {negative control }}\right)$. Those with affinity $\geq 2$ were considered positive clones; those with the highest binding affinities had their amino acid sequences analyzed.

Peptide synthesis. The CSSPIGRHC (NYZL1) and control CRIGSPHSC (svNYZL1) peptides were synthesized (Chinese Peptide Co., Hangzhou, China) using the standard solid-phase fluorenylmethyloxycarbonyl chloride chemistry. The products were purified to a minimum purity of $98 \%$ by high-performance liquid chromatography (HPLC). The sequence and structure of each peptide were characterized by mass spectrometry. FITCconjugated CSSPIGRHC and FITC-conjugated CRIGSPHSC (negative control) were also synthesized in the same manner.

Binding of a fluorescent peptide to cultured and exfoliated cells in the urine. The non-muscle-invasive bladder tumor BIU-87 cells $\left(\mathrm{n}=1 \times 10^{5}\right)$ were plated in glass-bottom dishes $(35 \mathrm{~mm}$; GBD-35-15; NEST) and cultured for $24 \mathrm{~h}$. The cells were washed 3 times with PBS and fixed with $4 \%$ paraformaldehyde at room temperature for $20 \mathrm{~min}$. After cells were blocked with $2 \%$ BSA for $1 \mathrm{~h}$, the FITC-NYZL1 and FITC-svNYZL1 peptides, respectively, were added for 1,4 or $12 \mathrm{~h}$ at $37^{\circ} \mathrm{C}$. After 3 washes, 4',6-diamidino-2-phenylindole (DAPI) was used to stain the nuclei for $5 \mathrm{~min}$ at room temperature and examined for fluorescence by laser scanning confocal microscopy (Olympus FluoView FV1000; Olympus, Tokyo, Japan). Meanwhile, the other bladder tumor cell lines, i.e. T24, E-J and 5637 as well as KC, SMMC-7721, SiHa and MCF-7 cells were further assessed by fluorescence microscopy using a
Table I. NYZL1 probe competitive assay.

\begin{tabular}{|c|c|c|c|c|c|c|}
\hline & \multicolumn{3}{|c|}{ NYZL1 } & \multicolumn{3}{|c|}{ NYZL1-FITC } \\
\hline & $2 \mu 1$ & $5 \mu 1$ & $10 \mu 1$ & $2 \mu 1$ & $5 \mu 1$ & $10 \mu 1$ \\
\hline \multicolumn{7}{|l|}{ BIU-87 cells } \\
\hline Competitive group & + & + & + & + & + & + \\
\hline Control group & & - & & + & + & + \\
\hline
\end{tabular}

+ , Probe addition.

procedure similar to that described above. FITC-conjugated synthetic NYZL1 peptides were incubated with the cells for $12 \mathrm{~h}$ at $37^{\circ} \mathrm{C}$. FITC-svNYZL1 peptides were used as negative controls. Mean cellular fluorescence intensity of 5 fields (up, down, left, right and middle) was used for statistical analysis. The percentage of positive (peptide bound) cells was calculated by dividing the number of green fluorescent cells with that of DAPI-stained cells in 5 high-power fields.

Urine samples were collected from 66 bladder cancer patients hospitalized in The First Hospital of Shanxi Medical University from August 2014 to January 2015. Of these patients, 9 had $\mathrm{T}_{\mathrm{a}}$ disease, $22 \mathrm{~T}_{1}$ disease, $21 \mathrm{~T}_{2}$ disease and $14 \mathrm{~T}_{3-4}$ disease as determined by pathological analyses. Meanwhile, 12 cystitis patients and 24 healthy individuals with similar ages were selected as controls. Exfoliated cells were obtained from $200 \mathrm{ml}$ of second morning voiding urine from patients with $\mathrm{BCa}$ and healthy adults. Urine samples were processed immediately after collection. After centrifugation for $10 \mathrm{~min}(1,300 \mathrm{rpm})$, the sediment was fixed with $4 \%$ paraformaldehyde at room temperature for $30 \mathrm{~min}$. Then, cells were smeared in the Laser confocal culture dish. The FITC-NYZL1 $(5 \mu \mathrm{mol} / \mathrm{l})$ and FITC-svNYZL1 $(5 \mu \mathrm{mol} / \mathrm{l})$ peptides were incubated with the cells for $1 \mathrm{~h}$ at $4^{\circ} \mathrm{C}$. After 3 washes, DAPI was used to stain the nuclei for $5 \mathrm{~min}$ at room temperature and examined for fluorescence by laser scanning confocal microscopy. Data analysis was carried out as described for cultured cells above.

Competitive experiment. The non-muscle-invasive bladder tumor BIU-87 cells $\left(\mathrm{n}=1 \times 10^{6}\right)$ were divided into 6 tubes for the 2 groups. NYZL-1 non-tagged and NYZL 1 FITC-tagged solutions both contained the peptides at $5 \mathrm{mg} / \mathrm{ml}$. Experimental details are listed in Table I. BIU-87 cells were treated with various probes, followed by staining in the dark for $30 \mathrm{~min}$; after two PBS washes, cells were fixed with $2 \%$ PFA, resuspended and assessed on a FACS analyzer. Experiments were repeated 3 times.

Peptide binding on human tissues. Peptide-based immunofluorescent histochemistry was performed to validate peptide binding to human bladder cancer. Frozen sections of human bladder cancer and adjacent normal appearing bladder mucosa tissues were performed according to the procedures described above. Fresh frozen sections were blocked with PBS/1\% BSA at $37^{\circ} \mathrm{C}$ for $30 \mathrm{~min}$, incubated with $100 \mu \mathrm{mol} / 1$ FITC-NYZL1 or FITC-svNYZL1 (negative control) at $4^{\circ} \mathrm{C}$ for $1 \mathrm{~h}$, and washed with PBS. After counterstaining of cells with DAPI, 
fluorescent images of tissue slides were acquired under a fluorescence microscope.

Tumor homing of the NYZL1 peptide in vivo. To test the tumor-homing ability, FITC-NYZL1 or FITC-svNYZL1 $(210 \mu \mathrm{g})$ was injected into the tail vein of human BIU-87 tumor-bearing mice. After $24 \mathrm{~h}$, mice were anesthetized and transcardially perfused with physiological saline to remove blood and unbound peptides. Tumors and control organs were excised and frozen in tissue-freezing medium (Jung Tissue Freezing Medium; Leica Microsystems, Wetzlar, Germany), cut into $6-\mu \mathrm{m}$ sections and arrayed on slides. The slides were then fixed with $4 \%$ paraformaldehyde for $20 \mathrm{~min}$ at $4{ }^{\circ} \mathrm{C}$, stained with DAPI for $8 \mathrm{~min}$ at room temperature and examined for fluorescence by laser scanning confocal microscopy (Olympus FluoView FV1000). Quantification of imaging data was accomplished using Image-Pro Plus 7.0 (Media Cybernetics, Bethesda, MD, USA).

Whole-organ imaging. For whole-organ imaging (29), tumor-bearing mice were intravenously injected with $200 \mu \mathrm{l}$ of $720 \mu \mathrm{M}$ fluorescein-conjugated peptide (FITC-NYZL1 or FITC-svNYZL1). After $30 \mathrm{~min}, 1,2,4,8$ and $12 \mathrm{~h}$, the mice were anesthetized and transcardially perfused with physiological saline to remove unbound peptides; tumors and organs were excised for examination. Organ imaging was performed under blue light using a multispectral fluorescence in vivo molecular imaging system (S-0010A; Science, Taiyuan, China).

Statistical analysis. All quantitative data are mean \pm standard error of the mean (SEM). According to normality test results, data were compared using one-way analysis of variance (ANOVA) followed by LSD post hoc test. Two-tailed $\mathrm{P}<0.05$ was considered statistically significant; adjusted P-values were used among subgroup comparisons. All statistical analyses were performed with SPSS 17.0 (IBM, Armonk, NY, USA) for Windows.

\section{Results}

Specific binding ability of the phages to BIU-87 bladder tumor tissue in vivo. To obtain the tumor-homing peptides by in vivo phage display biopanning against human bladder tumor cells, phage recovery from xenograft tumor tissues was assessed after every round of biopanning. The numbers of phages specifically binding to the tumor gradually increased: phage recovery rates were $1.324 \times 10^{-5}, 2.526 \times 10^{-5}$ and $5.738 \times 10^{-3} \mathrm{PFU} / \mathrm{g}$ in the first, second and third rounds, respectively (Table II). After the third round of screening, the numbers of phages that bound to the tumor tissue were enriched $\sim 4.334 \times 10^{2}$-fold compared to the first round.

After the third round of screening, we randomly selected 30 phage clones for ELISA. The results showed 24 phage clones with selective binding to BIU-87 cells compared with normal bladder cells (affinity $\geq 2.0$ ), including 10 individual phage clones with higher binding activity (affinity $>6.0$ ), which were isolated and sequenced. After translation into corresponding peptide sequences, eight phage clones displayed a predominant CSSPIGRHC motif; one displayed the CTMSNLKGC
Table II. Enrichment rate of phage screening in vivo.

\begin{tabular}{lcccc}
\hline $\begin{array}{l}\text { Panning } \\
\text { round }\end{array}$ & $\begin{array}{c}\text { Tumor } \\
\text { weight } \\
(\mathrm{g})\end{array}$ & $\begin{array}{c}\text { Selected } \\
\text { phage } \\
\text { (input PFU) }\end{array}$ & $\begin{array}{c}\text { Eluted } \\
\text { phage } \\
\text { (output PFU) }\end{array}$ & $\begin{array}{c}\text { Phage recovery } \\
\text { rate } \\
\text { (output/input)/g] }\end{array}$ \\
\hline 1 & 0.37 & $3.0 \times 10^{10}$ & $8.0 \times 10^{5}$ & $1.324 \times 10^{-5}$ \\
2 & 0.38 & $1.0 \times 10^{10}$ & $4.8 \times 10^{5}$ & $2.526 \times 10^{-5}$ \\
3 & 0.61 & $2.0 \times 10^{8}$ & $3.5 \times 10^{5}$ & $5.738 \times 10^{-3}$ \\
\hline
\end{tabular}

PFU, plaque forming units.

motif and another the CNNVLSQMC peptide motif. We used ExPASy/ProtParam and NCBI/BLAST databases to further analyze the CSSPIGRHC peptide. This motif had no homology with known genes and proteins. Thus, the CSSPIGRHC peptide is a new peptide sequence specifically binding to BIU-87 cells. This peptide (CSSPIGRHC) was named NYZL1 and synthesized for further testing. Since BIU-87 cells are Chinese human superficial bladder cancer cells, the present study is the first to explore the selected NYZL1 peptide with specific binding to Chinese bladder cancer.

To evaluate the specificity of phage clones for tumor homing, we compared the tissue distribution among the tumor, liver, kidney, lung, bladder and muscle tissues in each round of screening by immunohistochemistry. Phage peptides were enriched in tumor tissues and increased with each round of screening in vivo (Fig. 1B-D). The majority of phage clones preferentially bound to tumors rather than control tissues after the third screening (Fig. 1D-I). Various non-specific adsorption phages were observed in the liver and kidney tissues, perhaps since the phages were metabolized mainly by the liver and kidneys (Fig. $1 \mathrm{G}$ and $\mathrm{H}$ ). Only few phages binding to bladder, lung and muscle tissues were obtained after the third screening (Fig. 1E, F and I).

NYZL1 specifically binds to BIU-87 bladder cancer cells in vitro. To further verify the specific binding of NYZL1 to bladder cancer cells, whole cell binding assay was performed in vitro. The NYZL1 peptide was synthesized and conjugated with green fluorescent FITC at its amino terminus. Several bladder cancer cell lines (BIU-87, T24, E-J and 5637) were selected and other tumor cells (KC, SMMC-7721, SiHa and MCF-7) were used as controls. Immunofluorescence analysis demonstrated that the FITC-conjugated NYZL1 peptide strongly bound to BIU-87, T24, E-J and 5637 bladder cancer cells, compared with the control KC, SMMC-7721, SiHa and MCF-7 cells (Fig. 2; Table III). The FITC-NYZL1 peptide bound to BIU-87 cells with a similar strength compared to the other bladder cancer T24, E-J, 5637 cells (Fig. 2A-J). Meanwhile, the negative control FITC-svNYZL1 (the control peptide, CRIGSPHSC, is a scrambled variant of NYZL1, named svNYZL1) was used to determine whether peptide NYZL1 binds to BIU-87 bladder cancer cells in vitro. Fluorescein imaging revealed that NYZL1 specifically bound to BIU-87 bladder cancer cells. By contrast, no positive fluorescence was detected in the FITC-svNYZL1 peptide group (Fig. 2K). These results revealed that binding of the 

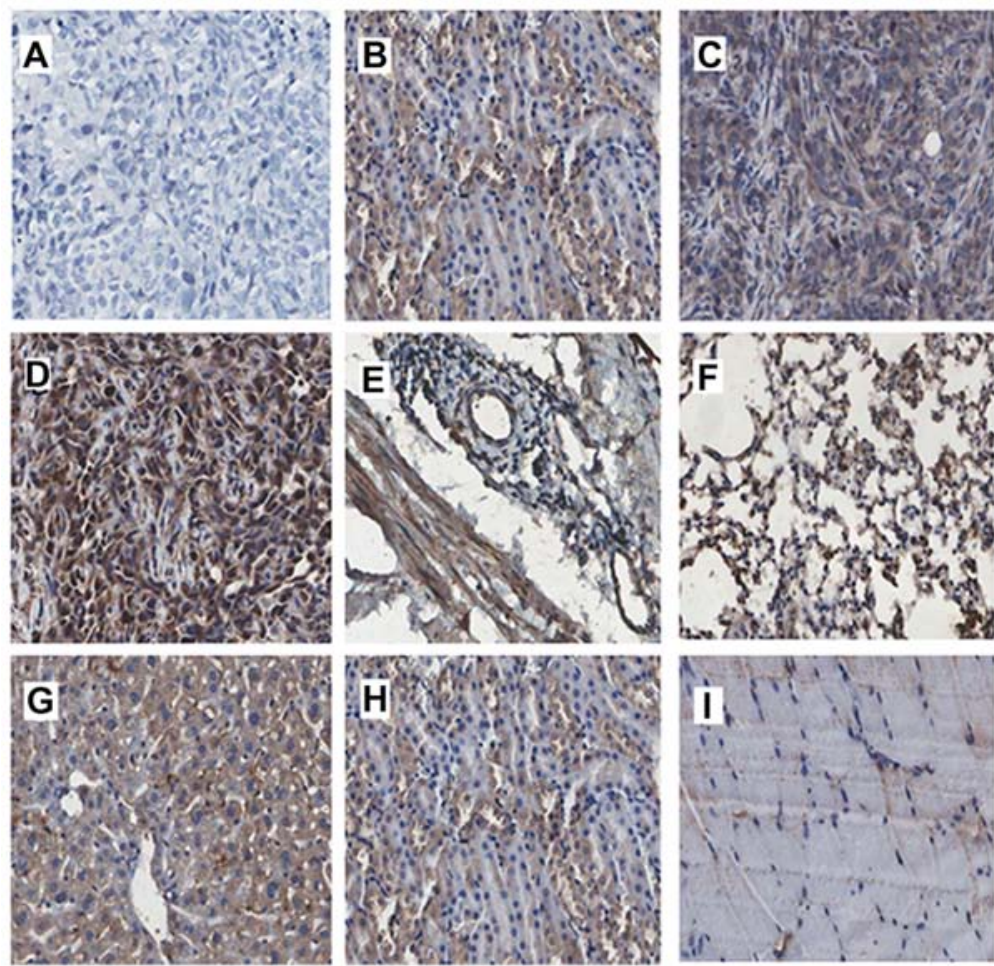

Figure 1. In vivo phage localization assays by phage immunostaining. Phage immunostaining confirms a significant difference in the binding rate and specificity between tumor and normal tissues (bladder mucosa, liver, kidney, lung and muscle). The phage binding rate was increased in tumor tissues with increasing screening round. (A) Tumor tissue in the control group. (B-D) First, second and third screening of phage tumor tissue sections. (E-I) Control tissues from the third round (E, bladder; F, lung; G, liver; H, kidney; and I, muscle) (magnification, x200; Aperio ScanScope).
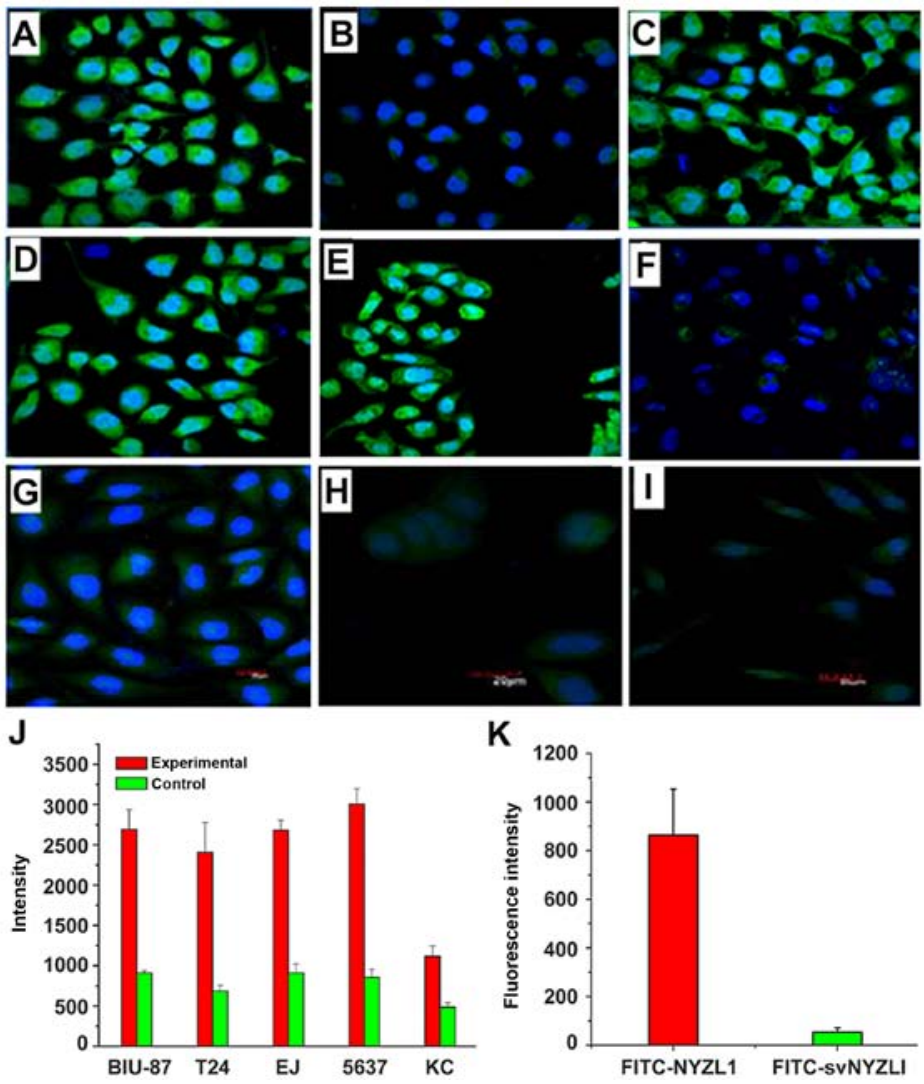

Figure 2. Binding of the NYZL1 peptide to cultured cells. Cell lines included BIU-87 (A and B), T24 (C), E-J (D), 5637 (E), KC (F) SMMC-7721 (G), MCF-7 (H) and SiHa (I). The cells were incubated with $1 \mu \mathrm{mol} / 1$ FITC-conjugated NYZL1 (A and C-I) or negative control FITC-svNYZL1 (B) for $6 \mathrm{~h}$ (green fluorescence). Cell nuclei were counterstained with $500 \mu \mathrm{g} / \mu$ l DAPI (blue fluorescence). Fluorescence in tumor cells was examined by Olympus FluoView FV1000 CLSM. Magnification, x400. A bar graph of NYZL1 specifically binding to bladder cancer cells (J); bars represent fluorescence intensity. Specificity of FITC-NYZL1 or FITC-svNYZL1 binding to BIU87 (K); bars represent fluorescence intensity. 
Table III. Average fluorescence values of fluorescent probe FITC-NYZL1 binding to different cancer cell lines.

\begin{tabular}{lccc}
\hline $\begin{array}{l}\text { Cell } \\
\text { lines }\end{array}$ & $\begin{array}{c}\text { No. of } \\
\text { samples }\end{array}$ & $\begin{array}{c}\text { Average fluorescence } \\
\text { value (mean } \pm \text { SEM) }\end{array}$ & $\begin{array}{c}\text { W-value } \\
\text { (Shapiro-Wilk test) }\end{array}$ \\
\hline BIU-87 & 10 & $3660.254 \pm 184.532$ & 0.927 \\
SMMC-7721 & 10 & $1138.822 \pm 127.238$ & 0.892 \\
MCF-7 & 10 & $720.534 \pm 178.783$ & 0.924 \\
SiHa & 10 & $615.094 \pm 98.903$ & 0.936 \\
\hline
\end{tabular}

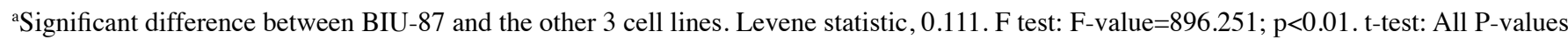
$<0.05$ except the P-value of MCF-7 and SiHa. Laser scanning confocal microscopy (Olympus Fluoview FV1000) was used.
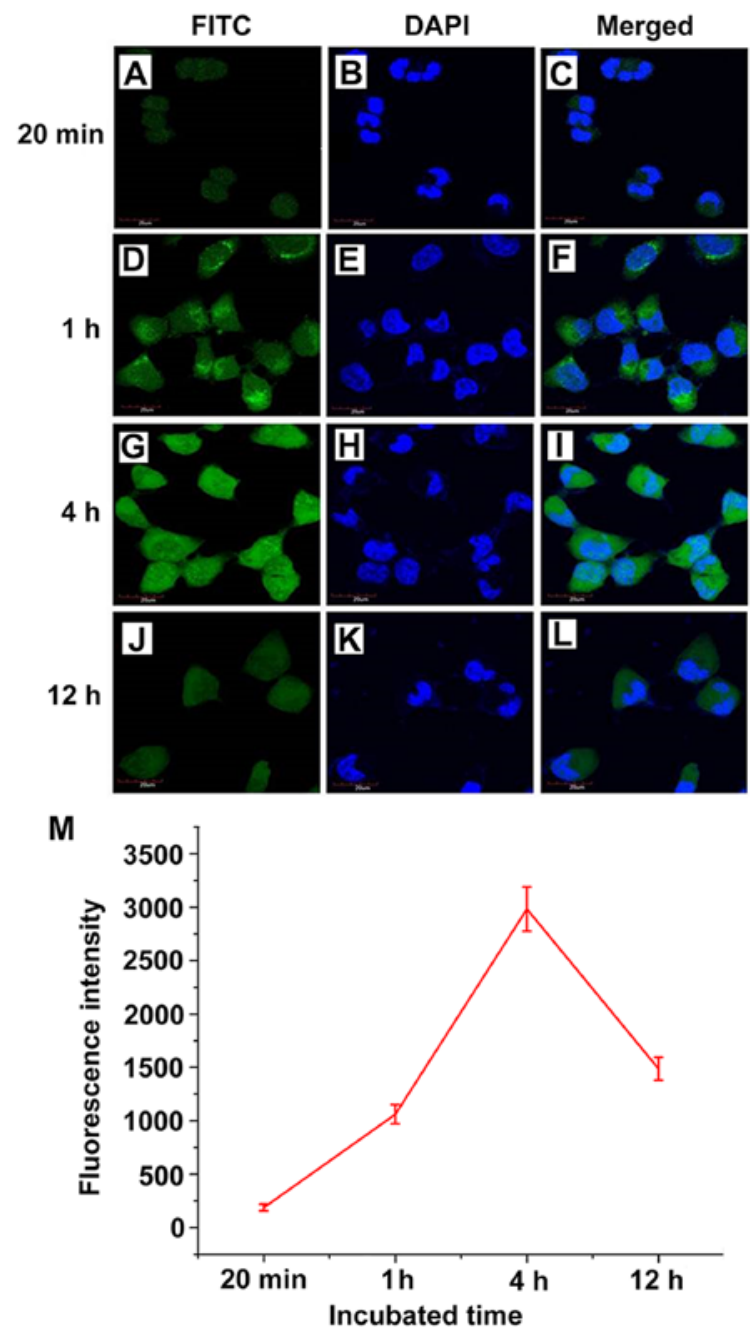

Figure 3. Internalization and nuclear translocation of NYZL1 by tumor cells. BIU-87 cells were incubated with $1 \mu \mathrm{mol} / 1$ FITC-conjugated NYZL1 for $20 \mathrm{~min}, 4$ and $12 \mathrm{~h}$. Cell were counterstained with $500 \mu \mathrm{g} / \mu \mathrm{l}$ DAPI. Fluorescence in the tumor cells was examined by Olympus FluoView FV1000 laser scanning confocal microscopy. (A-C) Tumor cells incubated with FITC-NYZL1 for 20 min. (D-F) Tumor cells incubated with FITC-NYZL1 for $1 \mathrm{~h}$. (G-I) Tumor cells incubated with FITC-NYZL1 for $4 \mathrm{~h}$. (J-L) Tumor cells incubated with FITC-NYZL1 for $12 \mathrm{~h}$. Magnification, x600. (M) Fluorescence intensity of incubated BIU-87 cells with $1 \mu \mathrm{mol} / 1$ FITC-conjugated NYZL1 for $20 \mathrm{~min}, 1,4$ and $12 \mathrm{~h}$.

NYZL1 peptide to other types of tumor cells was relatively weak compared to that to bladder tumor cells. Next, binding of the NYZL1 peptide to BIU-87 cells vs. different types of

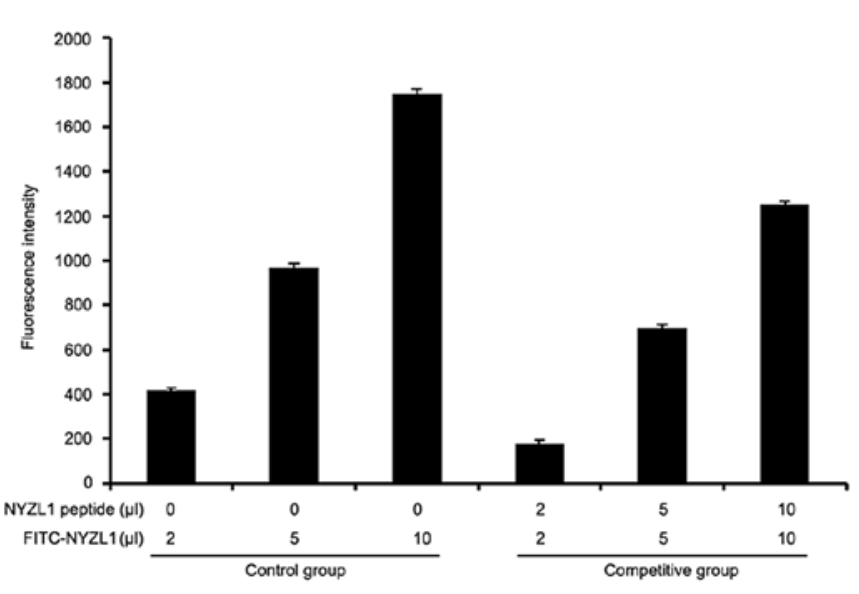

Figure 4. Specificity of NYZL1 in a competitive assay. BIU-87 cells were treated with FITC-NYZL1 alone or in combination with the NYZL1 peptide $(5 \mathrm{mg} / \mathrm{ml})$ and fluorescence intensity was measured.

tumor cells was measured by flow cytometry. Cellular fluorescence intensity in confocal images in the experimental (FITC-NYZL1) groups was measured at $20 \mathrm{~min}, 1,4$ and 12 h. Notably, the FITC-NYZL1 peptide bound to bladder cancer cells in a time-dependent manner. FITC-NYZL1 bound to BIU-87 cell cytoplasm at 20 min (Fig. 3A-C). After a 1-h incubation, fluorescein staining was not only detected in the cytoplasm, but also partially appeared in the nucleoplasm (Fig. 3D-F). After a 4-h incubation, fluorescein staining in the cytoplasm was significantly increased, with punctiform accumulation in the nucleus (Fig. 3G-I). After a 12-h incubation, fluorescein staining in the cytoplasm and nucleus gradually decreased (Fig. 3J-L).

Competitive experiment. Specificity of the NYZL1 target was assessed by a competitive assay, using FITC-NYZL1 and the NYZL1 peptide $(5 \mathrm{mg} / \mathrm{ml})$ to co-treat BIU- 87 cells. Fluorescence intensity of normal untreated BIU-87 cells was 15.24 \pm 5.1 ; after treatment of BIU-87 cells with 2, 5 and $10 \mu \mathrm{l}$ of FITC-NYZL1 alone, fluorescence intensities of 416.00 \pm 13.2 , $966.85 \pm 20.2$ and $1751.45 \pm 16.4$ were obtained, respectively, indicating a dose-dependent increase in fluorescence intensity. Meanwhile, BIU-87 cells co-treated with FITC-NYZL1 and NYZL1 peptides resulted in reduced fluorescence intensities of $180.45 \pm 12.4,696.30 \pm 16.3,1253.24 \pm 11.5$, for 25 and $10 \mu \mathrm{l}$ of 

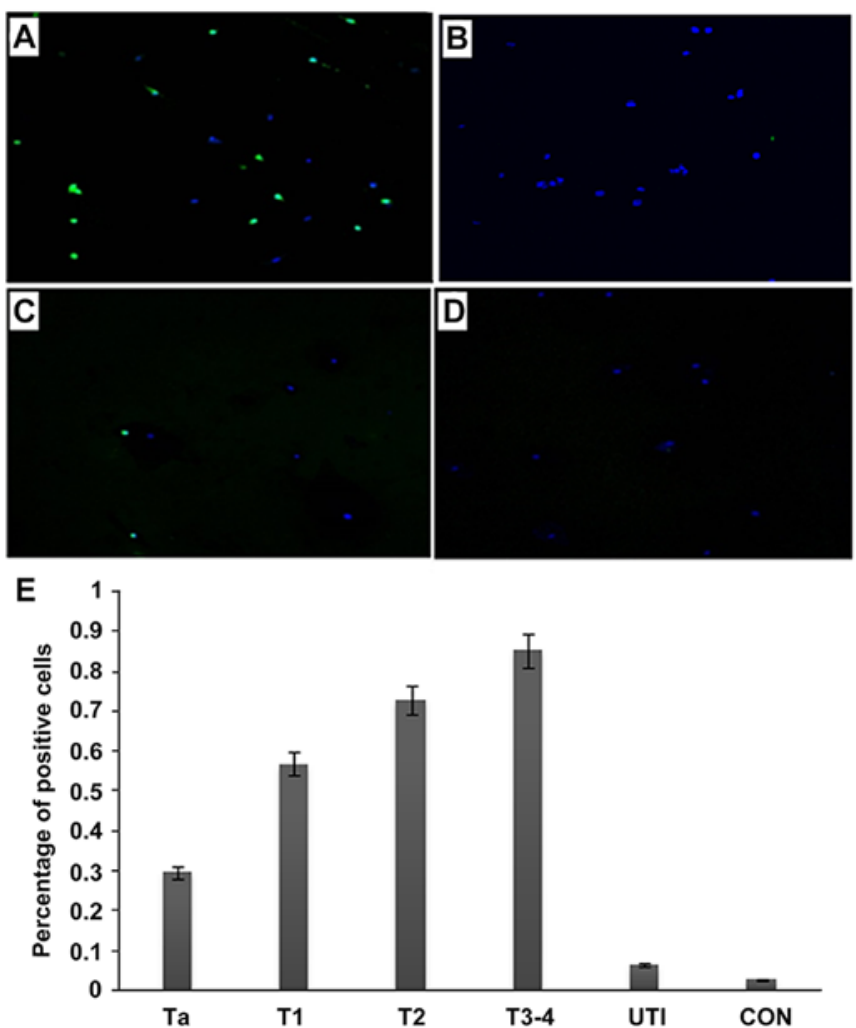

Figure 5. Detection of bladder tumor cells in the urine with the NYZL1 peptide. Urinary cells were collected from urine samples of bladder cancer (A and B), cystitis (C) and healthy control (D) patients. Cells were incubated at $4^{\circ} \mathrm{C}$ for $1 \mathrm{~h}$ with $5 \mu \mathrm{mol} / 1$ solutions of the FITC-NYZL1 peptide (A, C and D) or FITC-svNYZL1 (B), washed and stained with DAPI for counterstaining, and assessed by laser scanning confocal microscopy. Images are merged for the fluorescent peptide and DAPI staining. Magnification, x200. (E) A bar graph of tumor or control vs. percentage of positive cells. Numbers in the vertical axis represent percentage of positive cells. Ta-T3-4, bladder tumors UTI, urinary tract infection; CON, healthy control. The average intensities (integrated intensity per unit area) of fluorescence in the tumor and control groups, respectively, were calculated.

FITC-NYZL1, respectively, which were significantly different compared with the control group $(\mathrm{P}<0.05)$ (Fig. 4). These results indicated that the NYZL1 peptide blocked the binding sites of BIU-87 cells for NYZL1-FITC.

Detection of exfoliated cells in urine samples from bladder cancer patients. Next, we examined whether the target peptide could bind to cells in the urine from bladder cancer patients. The fluorescent NYZL1 peptide bound to exfoliated cells from urine sample of bladder cancer patients, unlike the control peptide FITC-svNYZL1 (Fig. 5A and B). Little fluorescence by peptide binding was detected with exfoliated cells from control urine samples of a cystitis patient and a healthy individual (Fig. 5C and D, respectively). The percentages of positive peptide bound cells were relatively high in all urine samples from cancer patients, with $10-48 \%$ (mean, 30\%) in Ta, 33-78\% (mean, 57\%) in $\mathrm{T} 1,58-87 \%$ (mean, $73 \%$ ) in $\mathrm{T} 2$, and $71-93 \%$ (mean, $85 \%$ ) in $\mathrm{T}_{3-4}$ stage tumors. In contrast, fewer positive cells were found in urine samples from patients with inflammation $(0-10 \%$; mean, $6.5 \%)$ and healthy individuals $(0-5 \%$; mean, $3 \%$ ) (Fig. $5 \mathrm{E})$. The binding rates of the FITC-NYZL1 peptide in urine exfoliated cells showed overt
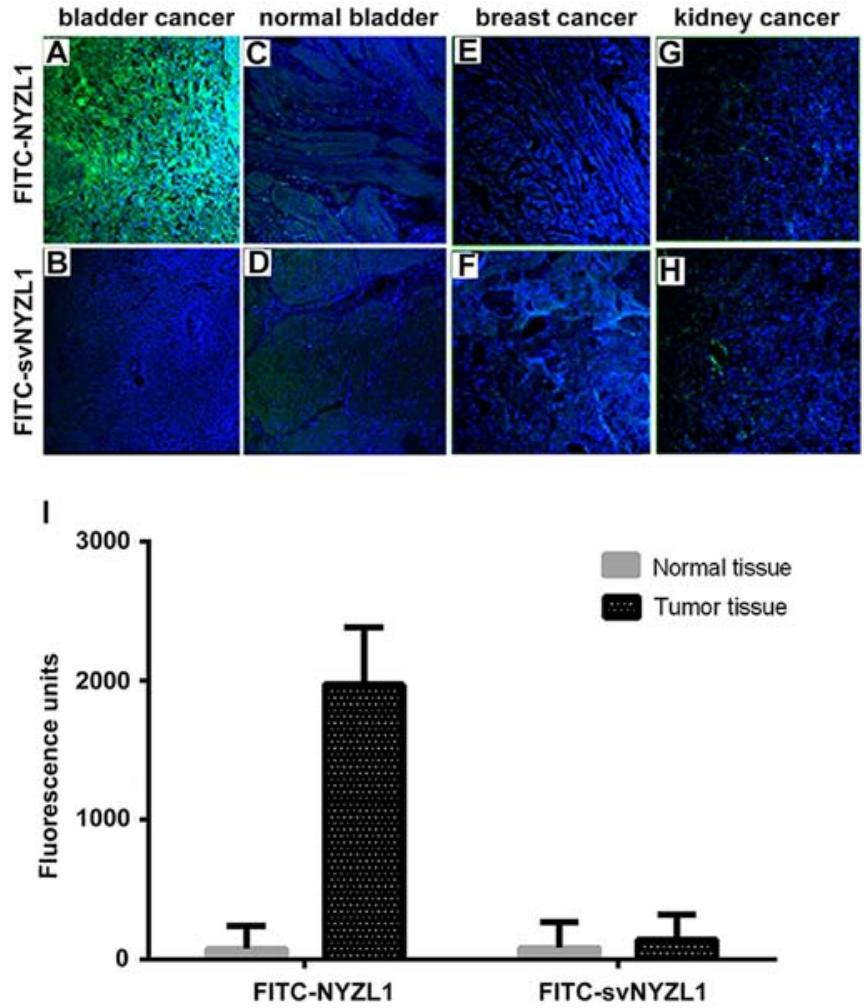

Figure 6. Selective binding of the NYZL1 peptide to human bladder tumor tissues. Frozen sections of bladder cancer (A and B), normal bladder (C and D), breast cancer ( $\mathrm{E}$ and $\mathrm{F})$ and kidney cancer $(\mathrm{G}$ and $\mathrm{H})$ tissues were incubated with $100 \mu \mathrm{mol} / 1$ FITC-NYZL1 or FITC-svNYZL1 (negative control) at $4^{\circ} \mathrm{C}$ for $1 \mathrm{~h}$, and counterstained with DAPI. Fluorescent images of tissue slides were visualized under a fluorescence microscope. Images are merged for the fluorescent peptide and DAPI staining. Magnification, x200. (I) Quantification of fluorescence intensity. The average intensities (integrated intensity/unit area) of fluorescence in the tumor $(n=5)$ and normal tissues $(n=3)$ were calculated.

differences in various stages of cancer; the higher the stage, the higher the specific binding rate. These findings suggested that the CSNRDARRC peptide is capable of distinguishing malignant cells from cells that exfoliate from bladder tumors, inflammatory lesions or normal tissues.

Selective binding of the NYZL1 peptide to human bladder tumor tissues. As shown in Fig. 6A, the synthetic FITC-NYZL1 peptide selectively bound to the primary bladder cancer tissue. Meanwhile, the scrambled control peptide FITC-svNYZL1 did not bind significantly to the tumor tissue (Fig. 6B). In contrast, limited binding of the FITC-NYZL1 peptide to the adjacent normal bladder tissue was observed (Fig. 6C). Quantification of fluorescence intensities in 5 primary bladder tumor and three normal bladder tissue specimens showed that NYZL1 bound to tumor tissues with a greater strength compared with normal tissues (Fig. 6I). In addition, the NYZL1 peptide did not bind to breast and kidney cancer specimens (Fig. 6E and G), suggesting the tumor-type specificity of the NYZL1 peptide.

Homing ability of the NYZL1 peptide in vivo. It was important to determine whether the NYZL1 peptide homes to bladder tumors, allowing in vivo detection and imaging. FITC-NYZL1 $(210 \mu \mathrm{g})$ was injected via tail vein into mice carrying BIU-87 xenograft tumors at $0.8-1.0 \mathrm{~cm}$ in diameter. Tumor 


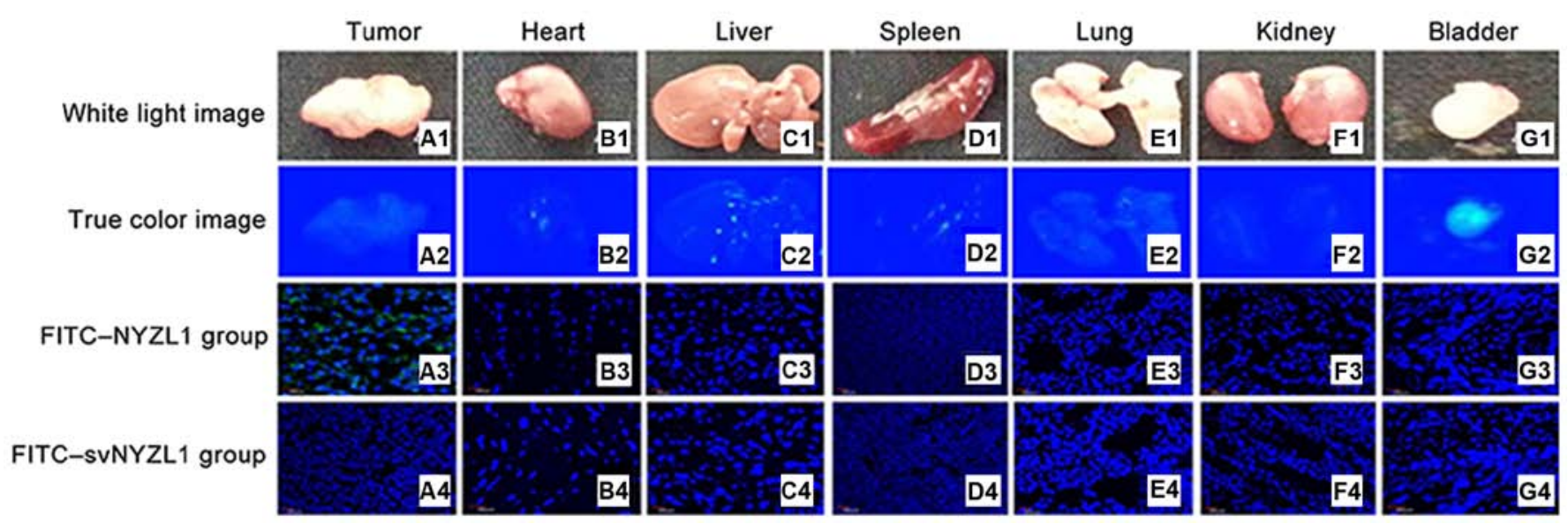

Figure 7. Representative light and fluorescence images of tumor tissues and organs from the experimental (FITC-NYZL1) (rows 2-3) and control (FITC-svNYZL1) (row 4) groups. Columns A-G show tumor tissue, heart, liver, spleen, lungs, kidneys and bladder. (A1-G1) Light images. (A2-G2) Images of fluorescence under blue light. (A3-G3) Fluorescence images of frozen sections of the tumor tissues and organs from the experimental group (FITC-NYZL1). Obvious green fluorescence can be found in the tumor tissue (A3). (A4-G4) Fluorescence images of frozen sections of the tumor tissues and organs from the control group (FITC-svNYZL1). No green fluorescence can be found in the tumor tissue (A4). Green regions indicate fluorescence of the FITC-NYZL1 probe, while blue regions represent fluorescence of the nucleus after DAPI counterstaining (magnification, x200).

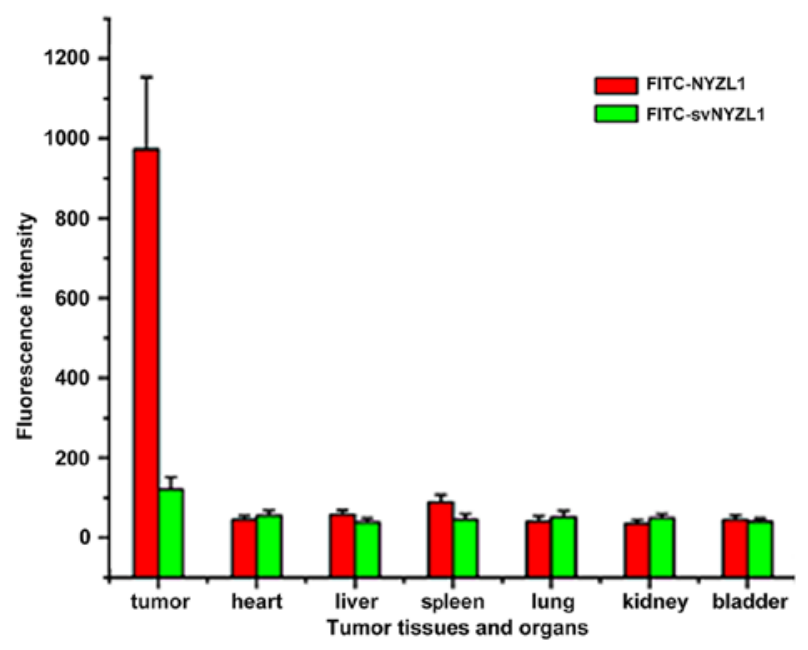

Figure 8. Quantification of fluorescence intensity. The average intensities (integrated intensity per unit area) of fluorescence in tumor and normal tissues $(n=3)$ were calculated.

tissues and control organs were then excised and processed for frozen sectioning at $24 \mathrm{~h}$ after injection of the peptide. Immunofluorescence showed that the FITC-NYZL1 peptide homed to the bladder tumor tissue (Fig. 7A3), but not to other organs such as the bladder, kidney, heart, lung, liver and spleen (Figs. 7 and 8) of tumor-bearing rats. By contrast, the scrambled control FITC-svNYZL1 peptide was not detected in the tumor tissue (Fig. 7A4). These results confirmed that the NYZL1 peptide specifically homed to bladder tumor tissues.

The NYZL1 peptide delivers fluorescein to tumor tissues for imaging detection. To determine whether FITC-NYZL1 accumulated in tumor tissues and can be visualized at the organ level, FITC-NYZL1 or FITC-svNYZL1 was injected intravenously into mice harboring human bladder tumor xenografts.
Various tissues and organs, including the implanted tumor, heart, liver, spleen, lung, kidney, and bladder were collected at $30 \mathrm{~min}, 1,2,4,8$ and $12 \mathrm{~h}$ after peptide injection. The isolated tissues and organs were examined by fluorescence microscopy in real-time to trace the fluorescent probe. At first a portion of the FITC-NYZL1 probe was found in the gallbladder as a result of metabolism by the liver; at this time, the liver and gallbladder showed fluorescent signals. Meanwhile, another portion of the FITC-NYZL1 probe was excreted with urine via the kidneys and bladder. The remaining portion was concentrated in the targeted tumor through blood circulation. As a result, fluorescent signals were found in the bladder and gallbladder soon after probe injection, and decreased overtime with gradual excretion. Meanwhile, fluorescence intensity in tumor tissues increased gradually: it peaked at 4-6 h, before decreasing from the $8 \mathrm{~h}$ time point. The FITC-NYZL1 probe had almost disappeared at $12 \mathrm{~h}$ after injection (Fig. 9A and B). Considering the presence of fluorescence in tumor cells despite the lack of signals at the organ and tissue levels, it can be inferred that NYZL1 shuttled the fluorescent dye to the designated tumor cells and specifically bound to the target tumor. Fluorescent microscopy results showed that the fluorescent signal was sustained for over $24 \mathrm{~h}$ at the molecular level, even when it disappeared at the tissue level. In addition, normal tissues and other organs were negative for fluorescence. Taken together, these findings confirmed the homing and binding affinity of the FITC-NYZL1 probe in bladder tumor cells.

\section{Discussion}

In the present study, we used a bladder tumor model established in BALB/c nude mice by subcutaneous transplantation of human NMIBC BIU-87 cells for in vivo biopanning of the phage display library. We isolated a cyclic 7 amino acid peptide (CSSPIGRHC, named NYZL1) that could specifically bind to the xenograft bladder tumor. We also showed that the peptide could recognize human bladder cancer cells, providing 

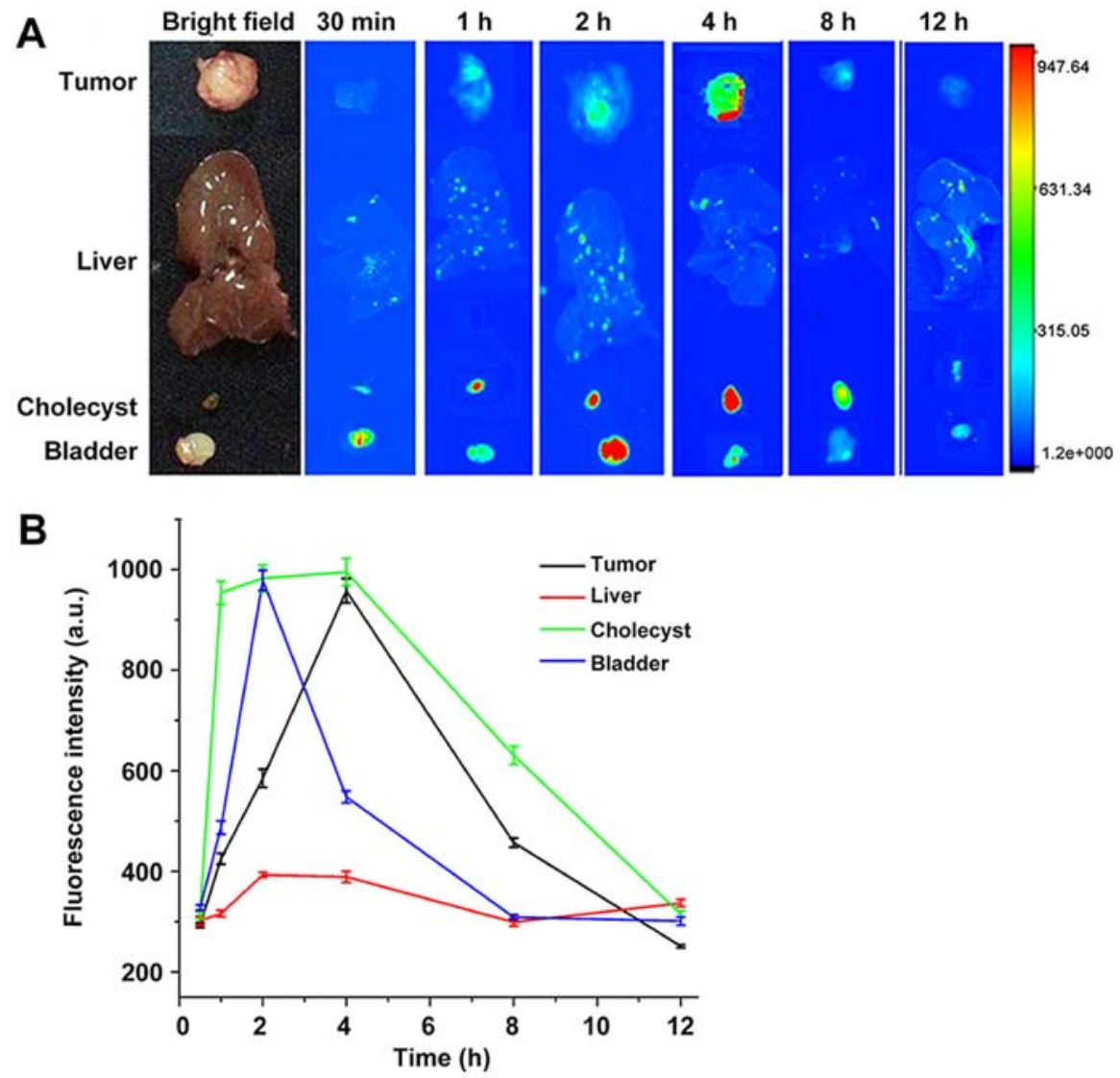

Figure 9. Fluorescence microscopy to trace in real-time the fluorescent probe in various tissues and organs of nude mice harboring xenografts. (A) Images at $30 \mathrm{~min}, 1,2,4,8$ and $12 \mathrm{~h}$ after injection of FITC-NYZL1. (B) Quantification of fluorescence intensity at $30 \mathrm{~min}, 1,2,4,8$ and 12 h after injection of FITC-NYZL1.

targeted delivery of fluorochrome to the tumor tissue. These data indicated that this peptide may be a new tool for optical molecular imaging diagnosis of NMIBC.

Cyclic peptides show better biological activity compared to their linear counterparts due to conformational rigidity (30). Indeed, the rigidity of cyclic peptides decreases the entropy term of the Gibbs free energy, therefore allowing the enhanced binding toward target molecules, or receptor selectivity. Another benefit from cyclic structures is the resistance to hydrolysis by exopeptidases due to the lack of both amino and carboxyl termini. Cyclic peptides can be resistant even to endopeptidases, as the structure is less flexible than linear peptides. Various cyclic peptides, though not all, can cross the cell membrane. In the present study, we screened a cyclic peptide (CSSPIGRHC) specifically binding to the human NMIBC cell line BIU-87.

To successfully establish the xenograft bladder tumor model in BALB/c mice, we used Matrigel, which significantly promotes the formation and proliferation of tumor xenografts. Bladder cancer tumors developed in all nude mice when BIU-87 cells were injected along with Matrigel; this greatly optimized animal utilization, reduced the experimental period, and provided an efficient experimental method for modeling of non-muscle-invasive bladder tumors. Matrigel was kept on ice before use, with pre-cooled pipettes, tips and tubes used for Matrigel preparation.

In vivo phage display panning has been employed to isolate organ homing phages from peptide libraries. In this method, first published by Pasqualini and Ruoslahti, phage libraries are injected into the tail vein of mice (31). Shortly thereafter, mice are sacrificed and the target organs removed. The organ-associated phages are retrieved and amplified from the homogenized tissues and the panning is repeated in another mouse. After 3-5 rounds of panning, several peptide motifs are typically identified for a given organ $(32,33)$. Using the same technology, tumor targeting peptides can be identified (34).

In the present study, we obtained a new peptide with a cyclic structure and specific binding to bladder tumor cell lines by in vivo phage display panning. This peptide exhibited specific binding to human bladder cancer cells in culture and tissues. The CSSPIGRHC phage preferential binding to cultured BLU-87 human bladder cancer cells was validated by ELISA. Fluorescence microscopy and AFM studies directly confirmed the specificity of the NYZL1 peptide. Our results revealed that NYZL1 had stronger binding to BIU-87 cells compared with the other tumor cells (kidney, breast and cervical cancer cells); however, this peptide bound to BIU-87 cells with a similar binding strength as the other bladder cancer cells studied, including T24, E-J and 5637. Fluorescent peptide overlay of tissue sections showed that the NYZL1 peptide bound to human bladder cancer sections but not to those of adjacent normal bladder or other tumor tissues. In addition, NYZL1 peptide-labeled bladder-exfoliated cells were found in urine samples from bladder cancer patients. These results indicate that the NYZL1 peptide can distinguish tumor-adjacent normal mucosa from bladder cancer, and is 
tumor type specific. This peptide may be useful as a targeting moiety for selective delivery of therapeutics, and constitutes a potential diagnostic probe for the detection of NMIBC.

To confirm the specific homing of NYZL1, we injected the FITC-NYZL1 probe into tumor-bearing mice. Immunofluorescence analysis showed that the FITC-NYZL1 peptide homed to bladder tumor tissues but not normal tissues in tumor-bearing rats. These results confirmed that the NYZL1 peptide specifically homes to the bladder tumor tissue. Furthermore, FITC-NYZL1 circulated throughout the whole body after intravenous injection. A portion of the FITC-NYZL1 probe was transported to the gallbladder via liver metabolism, with the liver and gallbladder showing fluorescent signals. Another portion of the FITC-NYZL1 probe was excreted in the urine. The remaining portion was concentrated in the targeted tumor. As a result, fluorescent signals appeared in the bladder and gallbladder soon after probe injection, decreasing overtime with gradual excretion. Meanwhile, fluorescent intensity in tumor tissues increased gradually, peaking at 4-6 h and decreasing from the $8 \mathrm{~h}$ time point; almost no signal was found at $12 \mathrm{~h}$ after probe injection (Fig. 5). Considering that fluorescence of tumor cells was positive at the microscopic level despite the lack of signal at the organ and tissue levels (Fig. 4), it can be concluded that NYZL1 transports the fluorescent dye to designated tumor cells and specifically binds to the target tumor. Fluorescence microscopy studies showed that the fluorescent signal was sustained for over $24 \mathrm{~h}$ at the molecular level even after it had disappeared at the tissue level. In addition, normal tissues and organs showed no fluorescent signals. Taken together, these studies confirmed the specificity and binding affinity of the FITC-NYZL1 probe in targeted tumor cells, with binding time more than $24 \mathrm{~h}$.

We attempted to identify peptides specifically targeting bladder tumors to guide optical molecular cystoscopic imaging for diagnosis of tiny or residual tumors. One potential application of such specific peptide homing to tumor vasculature is to deliver toxins or pro-drug molecules as targeted therapeutic agents to increase the efficacy of anticancer therapy and decrease the undesired systemic side-effects in other tissues $(14,35)$. The peptide NYZL1 is very appropriate for labeling with fluorophores for optical molecular cystoscopy diagnosis and treatment of NMIBC.

In summary, we successfully applied the in vivo phage display biopanning approach to identify the peptide CSSPIGRHC (NYZL1), which targets bladder cancer. The present study is the first to describe the NYZL1 peptide specifically binding to Chinese bladder cancer. We demonstrated the specificity and homing ability of NYZL1. Tumor homing peptide can be widely used in diagnostic and therapeutic models by conjugating them with anticancer drugs or imaging particles. The potential clinical applications include tumor localization to guide transurethral resection of bladder tumors, imaging detection, and targeted drug delivery for noninvasive bladder cancer.

\section{Acknowledgements}

The present study was carried out as part of a study on the 'Diagnosis of bladder tumor by targeting peptide mediated optical molecular imaging' (no. 81172444), supported by the National Natural Science Foundation of China.

\section{References}

1. Ploeg M, Aben KK and Kiemeney LA: The present and future burden of urinary bladder cancer in the world. World J Urol 27: 289-293, 2009.

2. Babjuk M, Oosterlinck W, Sylvester R, Kaasinen E, Böhle A and Palou-Redorta J; European Association of Urology (EAU): EAU guidelines on non-muscle-invasive urothelial carcinoma of the bladder. Eur Urol 54: 303-314, 2008.

3. Kirkali Z, Chan T, Manoharan M, Algaba F, Busch C, Cheng L, Kiemeney L, Kriegmair M, Montironi R, Murphy WM, et al: Bladder cancer: Epidemiology, staging and grading, and diagnosis. Urology 66 (Suppl 1): S4-S34, 2005.

4. Sylvester RJ, van der Meijden AP, Oosterlinck W, Witjes JA, Bouffioux C, Denis L, Newling DW and Kurth K: Predicting recurrence and progression in individual patients with stage Ta T1 bladder cancer using EORTC risk tables: a combined analysis of 2596 patients from seven EORTC trials. Eur Urol 49: 466-477, 2006.

5. Hall MC, Chang SS, Dalbagni G, Pruthi RS, Seigne JD, Skinner EC, Wolf JS Jr and Schellhammer PF: Guideline for the management of nonmuscle invasive bladder cancer (stages Ta, T1, and Tis): 2007 update. J Urol 178: 2314-2330, 2007.

6. Botteman MF, Pashos CL, Redaelli A, Laskin B and Hauser R: The health economics of bladder cancer: A comprehensive review of the published literature. Pharmacoeconomics 21: 1315-1330, 2003.

7. Riley GF, Potosky AL, Lubitz JD and Kessler LG: Medicare payments from diagnosis to death for elderly cancer patients by stage at diagnosis. Med Care 33: 828-841, 1995.

8. Liu JJ, Droller MJ and Liao JC: New optical imaging technologies for bladder cancer: Considerations and perspectives. J Urol 188: 361-368, 2012.

9. Weissleder R: Molecular imaging in cancer. Science 312: 1168-1171, 2006.

10. Kwon YS, Cho YS, Yoon TJ, Kim HS and Choi MG: Recent advances in targeted endoscopic imaging: Early detection of gastrointestinal neoplasms. World J Gastrointest Endosc 4: 57-64, 2012.

11. Mahmood U and Wallace MB: Molecular imaging in gastrointestinal disease. Gastroenterology 132: 11-14, 2007.

12. Cheng L, Davison DD, Adams J, Lopez-Beltran A, Wang L, Montironi $\mathrm{R}$ and Zhang S: Biomarkers in bladder cancer: Translational and clinical implications. Crit Rev Oncol Hematol 89: 73-111, 2014.

13. Muguruma N, Miyamoto $H$, Okahisa $T$ and Takayama $T$ : Endoscopic molecular imaging: Status and future perspective. Clin Endose 46: 603-610, 2013

14. Vlieghe P, Lisowski V, Martinez J and Khrestchatisky M: Synthetic therapeutic peptides: Science and market. Drug Discov Today 15: 40-56, 2010.

15. Lee SM, Lee EJ, Hong HY, Kwon MK, Kwon TH, Choi JY, Park RW, Kwon TG, Yoo ES, Yoon GS, et al: Targeting bladder tumor cells in vivo and in the urine with a peptide identified by phage display. Mol Cancer Res 5: 11-19, 2007.

16. Zhang $\mathrm{H}$, Aina $\mathrm{OH}$, Lam KS, de Vere White R, Evans $\mathrm{C}$, Henderson P, Lara PN, Wang X, Bassuk JA and Pan CX: Identification of a bladder cancer-specific ligand using a combinatorial chemistry approach. Urol Oncol 30: 635-645, 2012.

17. Gautam A, Kapoor P, Chaudhary K, Kumar R, Raghava GP and Raghava GP; Open Source Drug Discovery Consortium: Tumor homing peptides as molecular probes for cancer therapeutics, diagnostics and theranostics. Curr Med Chem 21: 2367-2391, 2014.

18. Babjuk M, Burger M, Zigeuner R, Shariat SF, van Rhijn BW, Compérat E, Sylvester RJ, Kaasinen E, Böhle A, Palou Redorta J, et al; European Association of Urology: EAU guidelines on non-muscle-invasive urothelial carcinoma of the bladder: Update 2013. Eur Urol 64: 639-653, 2013.

19. Geavlete B, Jecu M, Multescu R, Georgescu D and Geavlete P: HAL blue-light cystoscopy in high-risk nonmuscle-invasive bladder cancer - re-TURBT recurrence rates in a prospective, randomized study. Urology 76: 664-669, 2010. 
20. Smith GP: Filamentous fusion phage: Novel expression vectors that display cloned antigens on the virion surface. Science 228: $1315-1317,1985$

21. Li M, Gu FL, Li WB, Song YS, Zhou AR and Guo YL: Introduction of wild-type p53 gene downregulates the expression of H-ras gene and suppresses the growth of bladder cancer cells. Urol Res 23: 311-314, 1995.

22. Zhou HL, Zheng YJ, Cheng XZ, Lv YS, Gao R, Mao HP and Chen Q: Intercellular transfer of P-glycoprotein from the drug resistant human bladder cancer cell line BIU-87 does not require cell-to-cell contact. J Urol 190: 1069-1075, 2013.

23. Chen J, Ou-Yang X, Gao J, Zhu J, He X and Rong J: Knockdown of ribonuclease inhibitor expression with siRNA in non-invasive bladder cancer cell line BIU-87 promotes growth and metastasis potentials. Mol Cell Biochem 349: 83-95, 2011.

24. Fridman R, Benton G, Aranoutova I, Kleinman HK and Bonfil RD: Increased initiation and growth of tumor cell lines, cancer stem cells and biopsy material in mice using basement membrane matrix protein (Cultrex or Matrigel) co-injection. Nat Protoc 7: 1138-1144, 2012.

25. Lewis MT, Landua JD, Adams HC III and Medina D: A mystery wrapped in an enigma: Matrigel enhancement of mammary cell growth and morphogenesis. J Mammary Gland Biol Neoplasia 17: 99-101, 2012.

26. Green MR and Sambrook J: Molecular Cloning: A Laboratory Manual. Cold Spring Harbor Laboratory Press, New York, 2012.

27. Koivistoinen A, Ilonen II, Punakivi K, Räsänen JV, Helin H, Sihvo EI, Bergman M and Salo JA: A novel peptide (Thx) homing to non-small cell lung cancer identified by ex vivo phage display. Clin Transl Oncol 15: 492-498, 2013
28. Zhang L, Giraudo E, Hoffman JA, Hanahan D and Ruoslahti E: Lymphatic zip codes in premalignant lesions and tumors. Cancer Res 66: 5696-5706, 2006.

29. Pilch J, Brown DM, Komatsu M, Järvinen TA, Yang M, Peters D, Hoffman RM and Ruoslahti E: Peptides selected for binding to clotted plasma accumulate in tumor stroma and wounds. Proc Natl Acad Sci USA 103: 2800-2804, 2006.

30. Horton DA, Bourne GT and Smythe ML: Exploring privileged structures: The combinatorial synthesis of cyclic peptides. J Comput Aided Mol Des 16: 415-430, 2002.

31. Pasqualini R and Ruoslahti E: Organ targeting in vivo using phage display peptide libraries. Nature 380: 364-366, 1996.

32. Essler M and Ruoslahti E: Molecular specialization of breast vasculature: A breast-homing phage-displayed peptide binds to aminopeptidase P in breast vasculature. Proc Natl Acad Sci USA 99: 2252-2257, 2002.

33. Kolonin MG, Saha PK, Chan L, Pasqualini R and Arap W: Reversal of obesity by targeted ablation of adipose tissue. Nat Med 10: 625-632, 2004

34. Arap W, Pasqualini R and Ruoslahti E: Cancer treatment by targeted drug delivery to tumor vasculature in a mouse model. Science 279: 377-380, 1998.

35. Craik DJ, Fairlie DP, Liras S and Price D: The future of peptide-based drugs. Chem Biol Drug Des 81: 136-147, 2013. 